\title{
Impact of a Scholar Based Program on the Social Skills and Sexual Health of Colombian Teens: A Prospective Randomize Controlled Study
}

\author{
Ana F. Uribe ${ }^{1}$, Teresita Sevilla ${ }^{2}$, Linda T. Orcasita ${ }^{3}$, Ana M. Sanabria ${ }^{4}$, \\ Julián A. Tamayo ${ }^{5}$, Luz Á. Torres-de la Roche ${ }^{6}$, Rudy L. De Wilde ${ }^{7}$ \\ ${ }^{1}$ Doctor in Clinical and Health Psychology, Faculty of Psychology of Universidad Pontificia \\ Bolivariana of Bucaramanga, Colombia. \\ ${ }^{2}$ Doctor in Sociology. Group for Research Measurement and Psychological Evaluation, Human Life \\ Cycle, Risk and Socialization Branch of Pontificia Universidad Javeriana of Cali, Colombia. \\ ${ }^{3}$ Psychologist Magister in Familial Studies. Group for Research Measurement and Psychological \\ Evaluation, Human Life Cycle, Risk and Socialization Branch of Pontificia \\ Universidad Javeriana of Cali, Colombia. \\ ${ }^{4}$ Magister in Community Psychology. Group for Research Measurement and Psychological \\ Evaluation, Human Life Cycle, Risk and Socialization Branch of Pontificia \\ Universidad Javeriana of Cali, Colombia. \\ ${ }^{5}$ Statistician Master in Logistics. Institución Universitaria Colegios de Colombia. \\ ${ }^{6}$ Gynecology and Reproductive Health Specialist. Department of Gynecology and Obstetrics of Carl \\ von Ossietzky University Medical School, Oldenburg, Germany. \\ ${ }^{7}$ Professor and Director of the Clinic of Gynecology, Obstetrics and Gynaecological \\ Oncology, University Hospital for Gynecology, Pius-Hospital Oldenburg, Medical Campus \\ University of Oldenburg, Germany \\ ${ }^{7}$ rudy-leon.dewilde@pius-hospital.de
}

\begin{abstract}
:
Objective: To evaluate the impact of the program "Know and Do to Be Well" on the social skills and sexual health of Colombian scholars of 5 different cities.

Methodology: Prospective, randomized controlled study realized between 2012- 2013. The experimental group attended workshops about HIV, sexuality, STI, social skills and self-perceptions during 4 months. Controls attended any. For the quantitative assessment, questionnaires of social interaction skills were applied prior and at end of the intervention, and analyzed through STATA and Differences in Differences statistical packages. Age and gender were adjusted by Mann Whitney test with a 5\% level of significance. For the qualitative assessment, three focus groups were made one year later; discussions were transcribed in Word 7.0, and analyzed by authors.
\end{abstract}

Results: A total of 358 scholars aged 10-20 years (mean 14.5) participated; $168(46,93 \%)$ in the experimental group and 190 (53,07 \%) as controls. The quantitative assessment showed a positive significant effect on 60\% $(p=<0.05)$ of social interaction skills of scholars, mainly, improving their knowledge on HIV and sexual and reproductive health. Also a reduction of the antisocial and criminal behavior was observed. The qualitative assessment showed the same positive effects, but condom negotiation and sexual decision-making processes remained affected by gender and cultural influences.

Conclusions: Health scholar based programs motivate adolescents to adopt healthier sexual behaviors and strengthen their personal skills. However, decision-making issues are difficult, so scholars still need continuous support from parents and teachers to empower them against social pressures.

Keywords: Teens, adolescent's health, reproductive health, health center based school evaluation, impact on health, HIV, sexual education, sexual behavior. 


\section{INTRODUCTION}

In 2010, 19,5\% of Colombian female adolescents between 15-19 years were or have been pregnant, and $14 \%$ of Colombian women between 15-24 years-old reported to had their first intercourse before reaching their $18^{\text {th }}$ birthday, but only $50 \%$ of them used a condom (1). Besides this data, in the investigation conducted by Uribe et al (2) among Colombian adolescents, a direct relation was found between risk sexual health conducts and problematic behaviors, such as antisocial tendencies and psychopathological disorders. At greatest risk were adolescents in Valle del Cauca, a state at southwest Colombia, where youth were found to be exposed to high risk factors, like beginning of sexual intercourse at the age of 13 , consumption of psychoactive substances and low self-care conscientious. Furthermore, the authors reported problems related with the network services for youth, specifically low offer of Sexual and Reproductive Health [SRH] services, incomplete sex education programs, and teachers and local health providers with insufficient expertise on SRH issues. Subsequently to this evidence, Colombian teens require to move forward with innovative approaches to their SRH in order to improve their self- care and social skills.

In this context, the group of investigation "Measurement and Psychological Evaluation "of Javeriana University of Cali, Colombia, developed the interventional program "Know and Do to be Well" [KDW].This program of four-month duration aimed to improve the sexual health and social skills of scholar adolescents from five cities in Colombia. To achieve its target, the program was designed with a biopsychosocial approach, taking into account that the SRH is a crucial part of the general health and human development, which is affected by the knowledge, the culture and the individual mental health (3-6). During the intervention, the program used validated and adjusted health communication strategies (7), to deliver information about adolescence, sexuality, HIV/STI, social skills, self-care and self-efficacy. Self efficacy is defined as the perceived ability of an individual to perform a protective action (8). In the present article we presented the results of the evaluation of KDW, which was made to estimate the impact of this scholar based program on the sexual health and social skills of the participant adolescents.

\section{MeTHODOLOGY}

The program KDW and evaluation were conducted with adolescents of 12 secondary schools across five different cities of Colombia (Armenia, Bogota, Cali, Manizales and Pasto). Sites represented different urban regions of the country and a wide-ranging of socio-economic status. Inclusion criteria included middle and high-school adolescents available to attend at least $90 \%$ of activities of the program. Exclusion criteria included youth who would no be attending their regular scholar schedule, who do not want to participate, or with mental disabilities which preclude their ability to participate. Trained facilitators provided participants with information about the study, the specific sessions and data collection times of the program. Interested scholars and parents were scheduled to meet with project research staff to obtain additional information, be consented and verify contact information. Based on ethics considerations, non-participants were not asked about their reasons.

Prior to the intervention, the voluntary participants of each school were randomized to the experimental or to control group by means of a computed random sampling. Sample size was calculated in 268 participants, with a 5\% alpha-error and 95\% of confidence interval.

\section{STATISTICAL ANALYSIS}

The experimental group was present at four monthly workshops with maximum 25 participants, to assure effective communication and active participation by all teens. The curricula included information about adolescence and HIV; Sexuality and STI; social skills, and self-care (Table 1). The workshops were leaded by qualified professionals, who received proper training before the implementation of the program. A full description of KDW program development, implementation and questionnaires are available elsewhere. The evaluation of KDW was made using both quantitative and qualitative methodologies.

The quantitative evaluation was executed by means of a questionnaire including 100 questions $(2,9-$ 13). It was applied to scholars of the experimental and control group prior and after the completion of the program. This questionnaire allows the assessment of changes in the knowledge, attitudes and beliefs that participants have in regards to their own knowledge about SRH, HIV/AIDS, social interaction skills, antisocial behaviors and self-efficacy. 
Table 1. Description of topics tackled during workshops

\begin{tabular}{|l|l|}
\hline WORKSHOP & SUMMARY \\
\hline Adolescence and & $\begin{array}{l}\text { The distinctive characteristics and the bio psychosocial changes of this stage of life were } \\
\text { elucidated, with emphasis on aspects that present difficulties for parents, children and } \\
\text { experts. General concepts, forms of transmission and prevention of HIV, as well as } \\
\text { myths and stereotypes/stigmas associated with the virus were discussed in detail. }\end{array}$ \\
\hline $\begin{array}{l}\text { Sexuality and } \\
\text { sexually } \\
\text { transmitted } \\
\text { infections. }\end{array}$ & $\begin{array}{l}\text { Sexuality was discussed through an integral perspective, that means, not only from } \\
\text { functional of biological factors, but also integrating the interaction between these and the } \\
\text { psychological and sociocultural factors. This implies the conjunction of biological, } \\
\text { psychological dimensions, and socio-affective relationships. Additionally, STI were } \\
\text { tackled, including the forms of transmission and prevention of the diseases. }\end{array}$ \\
\hline Social abilities & $\begin{array}{l}\text { In order to establish good interpersonal relationships and allow youth to express their } \\
\text { views encompassing the world, discussions included: initiation and maintenance of } \\
\text { conversations; assertive, passive and aggressive communication; conflict resolution; } \\
\text { handling and expression of emotions. This was especially relevant for those with } \\
\text { recognized difficulties in communication and relationship between parents and children. } \\
\text { Violence was not in deep learned. }\end{array}$ \\
\hline Self-perceptions & $\begin{array}{l}\text { This workshop tackled self-concept, self-portrait and self-esteem as key elements in the } \\
\text { construction of practices of self-care. These must be recognized as inherent } \\
\text { characteristics of the personality, which are closely linked to the way in which } \\
\text { adolescents live - either in a healthy way or incurring in high-risk behaviors. They are } \\
\text { therefore the basis of safety and self confidence. }\end{array}$ \\
\hline
\end{tabular}

The qualitative evaluation was carried out one year after the completion of the program through 3 different focus groups that were formed with participants of the experimental group. This tool offers a suitable space for discussion, which allows identifying common aspects in individual experiences during an intervention. The discussed matters were: perceived changes in the knowledge, attitudes and beliefs about the topics tackled during the workshops; self efficacy and response efficacy, that is successful experiences of application of knowledge and skills obtained throughout the intervention. Also the participants were allowed to talk about other experiences, and give recommendations to the program.

The results of the quantitative evaluation were analyzed through the STATA package version 9 and the "Differences in Differences" statistical analysis method (14), which allows establishing the magnitude of the changes of each variable, giving positive or negative points if the effect reinforced o diminished the studied variable. Data about social demographics was also included in order to improve the precision of estimations, to avoid contamination of impact results attributable to the program, and controlling confounding factors between the experimental and the control group. Age and gender were adjusted by Mann Whitney test, and $\mathrm{P}$ values $<0.05$ level were considered statistically significant. The discussions of the focus groups were transcribed into Word 7.0, and the answers classified according the mentioned topics. There was no minimal requirement for attendance for analysis inclusion.

An informed consent form was signed by each participant and, in case of minors, also their parents or guardians. There were any incentives to participate. The project was approved by the Ethics Committee of the Faculty of Humanities Education and Social Sciences of Pontificia Universidad Javeriana of Cali.

\section{RESULTS}

From a total of 1056 pupils attending the 12 schools, a final sample of 358 adolescents was obtained with $190(53,07 \%)$ in the control group and $168(46,93 \%)$ in the experimental group (Table 2). There was an equitable distribution of males and females in both groups. The age of participants ranged between 10-20 years (mean 14.5 +/- 2.1), reflecting the great age dispersion of pupils in Colombian public schools. Comparing to controls, the experimental group had a significantly higher number of students who were between 8-11 years $(\mathrm{p}<0.05)$, belonged to a higher social stratum $(\mathrm{p}<0.05)$, middle or high-middle income. And had a less-dispersed schooling level $(\mathrm{p}<0.05)$, that means, they were in the mean educational level expected for their age The differences in age, sex and schooling were adjusted by the Difference-in-Difference model for the quantitative analysis. 95\% of participants of the experimental group attended and completed all programmed activities. One year later, 27 students (mean 
$8+/-1$ ), between 13 and 17 years of age, $40 \%$ males and $60 \%$ females, attended 3 different focus groups for the qualitative analysis.

Table 2. Demographic characteristics of the groups.

\begin{tabular}{|c|c|c|c|c|c|c|}
\hline & \multicolumn{4}{|c|}{ Group } & \multirow{3}{*}{$\begin{array}{l}\text { Chi } 2 \\
p\end{array}$} \\
\hline & & \multicolumn{2}{|c|}{ Control } & \multicolumn{2}{|c|}{ Experimental } & \\
\hline & & $n=190$ & $\%$ & $n=168$ & $\%$ & \\
\hline \multirow{5}{*}{ City } & Bogotá & 45 & $23,7 \%$ & 17 & $10,1 \%$ & \multirow{5}{*}{0,067} \\
\hline & Pasto & 47 & $24,7 \%$ & 35 & $20,8 \%$ & \\
\hline & Manizales & 81 & $42,6 \%$ & 39 & $23,2 \%$ & \\
\hline & Armenia & 0 & $0,0 \%$ & 4 & $2,4 \%$ & \\
\hline & Cali & 17 & $8,9 \%$ & 73 & $43,5 \%$ & \\
\hline \multirow{4}{*}{$\begin{array}{l}\text { Age } \\
\text { (years old) }\end{array}$} & $8-11$ & 9 & $4,8 \%$ & 27 & $16,5 \%$ & \multirow{4}{*}{0,004} \\
\hline & $12-15$ & 110 & $59,1 \%$ & 84 & $51,2 \%$ & \\
\hline & $16-18$ & 63 & $33,9 \%$ & 51 & $31,1 \%$ & \\
\hline & $19-20$ & 4 & $2,2 \%$ & 2 & $1,2 \%$ & \\
\hline \multirow{2}{*}{ Gender } & Male & 83 & $43,7 \%$ & 90 & $53,6 \%$ & \multirow{2}{*}{0,062} \\
\hline & Female & 107 & $56,3 \%$ & 78 & $46,4 \%$ & \\
\hline \multirow{4}{*}{$\begin{array}{l}\text { Social } \\
\text { Stratum* }\end{array}$} & Stratum 1 & 111 & $59,0 \%$ & 39 & $24,5 \%$ & \multirow{4}{*}{0,000} \\
\hline & Stratum 2 & 58 & $30,9 \%$ & 97 & $61,0 \%$ & \\
\hline & Stratum 3 & 16 & $8,5 \%$ & 21 & $13,2 \%$ & \\
\hline & Stratum 4 & 3 & $1,6 \%$ & 2 & $1,3 \%$ & \\
\hline \multirow{6}{*}{ Scholar grade } & Sixth & 29 & $15,4 \%$ & 26 & $15,5 \%$ & \multirow{6}{*}{0,000} \\
\hline & Seventh & 47 & $25,0 \%$ & 20 & $11,9 \%$ & \\
\hline & Eighth & 32 & $17,0 \%$ & 18 & $10,7 \%$ & \\
\hline & Ninth & 28 & $14,9 \%$ & 7 & $4,2 \%$ & \\
\hline & Tenth & 33 & $17,6 \%$ & 80 & $47,6 \%$ & \\
\hline & Eleventh & 19 & $10,1 \%$ & 16 & $9,5 \%$ & \\
\hline
\end{tabular}

*Social stratum according to family income level: 1 and 2=low; $3=$ middle, $4=$ high middle

Boldface indicates statistical significance $(\mathrm{p}<0.05)$

The quantitative analysis (Table 3), showed that after intervention the experimental group changed significantly ( $p<0.05)$ in $60 \%$ of studied variables mainly improving the knowledge on HIV (29.79 points), diminishing the erroneous knowledge on SRH matters (15.23 points), and strengthening their previous correct knowledge on SRH (3.63 points).It was also observed a strengthening of their selfperceived susceptibility to an unexpected intercourse, pregnancy or STI (2.93 points), as well their ability to assume protective actions were increased (self-efficacy $=1.16$ points). Related to the expression of emotions and feelings, they improved their search of sensations ( 2.45 points), and turned their negative or neutral attitude to a positive level, or reinforced their prior positive attitudes (negative attitude $=3.57$ points; neutral attitude $=3.51$ points; positive attitude $=1.06$ points). Unless violence was not in deep learned, it was observed a diminishing in the antisocial and criminal behaviors (4.32 points) of participants. In this Table are presented the results of the experimental group, because the control group showed any significant change in the studied variables.

Within focus groups, participants reported a high level of satisfaction with the program, expressing that the learned lessons increased their sense of responsibility towards themselves and their partners. The topics most interesting for females were contraceptive methods, condom use and prevention of HIV, while the males were more concerned with condom use and STI. Alcohol consumption was an emergent topic. Females reported light consume, while males reported a frequent consume, sometimes until they felt drunk, recognizing that is difficult to control its consumption when "Ifeel depressed or being already drunk".

The most important self-perceived changes reported during focus groups were related with sexuality, HIV/STI, condoms and self control. Participants expressed have enhanced their perception on SRH issues, as well improved their ability to recognize risks and protective health factors related to their SRH. The main prophylactic measurements mentioned were "condom use, avoid promiscuity, conscientious couple selection and access to HIV testing after high-risk sexual contact". Nevertheless, it was observed that there is no absolute clarity on sexual practices that demand specific protection, such as anal and oral sex. More over, it was highlighted that there exists a significant difference between what adolescents know about safe sex and what they actually do in practice. 
Impact of a Scholar Based Program on the Social Skills and Sexual Health of Colombian Teens: A Prospective Randomize Controlled Study

Table 3. Impact level on social skills and sexual health knowledge.

Experimental group.

\begin{tabular}{|l|c|c|}
\hline Scale & Size of the effect & p- Value \\
\hline Basic social skills & $-0,462$ & 0,679 \\
\hline Skills to make friends & $-0,113$ & 0,929 \\
\hline Conversational skills & $-0,842$ & 0,518 \\
\hline Skills related to emotions and feelings & $-0,718$ & 0,582 \\
\hline Skills to resolve problems & $-2,073$ & 0,208 \\
\hline Skills to establish relationships with adulthoods & $-1,411$ & 0,243 \\
\hline Search of sensations & 2,459 & $\mathbf{0 , 0 1 8}$ \\
\hline Resolution of conflicts & 4,133 & 0,276 \\
\hline Antisocial behaviors & 2,159 & 0,081 \\
\hline Criminal behaviors & 2,025 & $\mathbf{0 , 0 3 3}$ \\
\hline Antisocial and criminal behaviors, total & 4,323 & $\mathbf{0 , 0 4 3}$ \\
\hline Positive attitude & 1,066 & $\mathbf{0 , 0 1 0}$ \\
\hline Negative attitude & 3,577 & $\mathbf{0 , 0 0 0}$ \\
\hline Neutral attitude & 3,518 & $\mathbf{0 , 0 0 0}$ \\
\hline Susceptibility & 2,936 & $\mathbf{0 , 0 0 0}$ \\
\hline Self efficacy & 1,161 & $\mathbf{0 , 0 0 5}$ \\
\hline Correct knowledge on SRH & 3,633 & $\mathbf{0 , 0 0 6}$ \\
\hline Incorrect knowledge on SRH & 15,230 & $\mathbf{0 , 0 0 0}$ \\
\hline Knowledge on HIV & 29,798 & $\mathbf{0 , 0 0 0}$ \\
\hline AIDS phobia & 2,323 & 0,409 \\
\hline
\end{tabular}

$\mathrm{SHR}=$ sexual and reproductive health.

Boldface indicates statistical significance $(\mathrm{p}<0.05)$

When asked about what is known regarding practices of their friends, and other males and females in their community or social circle, participants reported very low levels of consistent condom use, or malpractices such as "placement only at the time just before ejaculation". Males attributed the high tendency to overlook risks to "the excitement of the moment", and the desire to "have direct contact with my partner without a barrier like a condom". On the other hand, females assigned more emotional than physical reasons for not using condoms, such as "feeling closer to her partner". Besides, participants reported that some cases of regular current condom use are merely part of a "corrective strategy" after a STI or an unintended pregnancy. Participants also admitted that the low frequency of condom use is not related to the level of knowledge about the implicit risks of unprotected coitus, but rather to the difficulty that women have to refuse unprotected intercourse, and the "absence of awareness of some males, whom in many cases seek pregnancy intentionally".

In regard to the processes of condom negotiation, females reported that their friends had difficulty refusing unprotected sex with their regular partners; especially "they have fear of be abandoned by their boyfriend". For males, little intention to negotiate condom use was expressed. Interestingly, males were observed to have a tendency to justify or pass nonjudgmental attitudes towards their male friends, while females were more thoughtful and proactive, that is, they criticized this attitude and expressed their intention to have protected intercourses in the near future. By other hand, sexual active adolescents whom showed more interest and were more actives during the discussions, expressed to have limited access to family planning methods and health services, because of their associated cost ant their inability to afford them.

Finally, participants expressed a good level of satisfaction with the communicating strategies used during the interventional activities, facilitating them a posterior open dialogue about SRH with their peers and parents. However, participants recognized the existence of a generational difference with their parents or other adults, being youth more affective and showing less negative attitudes toward people living with HIV. In addition, they expressed that "well informed adults are more open to listening to their children's opinions regarding SRH matters"; therefore, they recommended extending the KDW coverage to parents. 


\section{DISCUSSION}

Interventional programs that encourage adolescents to take an active role in their sex education are able to offer better knowledge on sexual health, and promote enhanced social skills in youth that strengthen healthy sexual behaviors, negotiation abilities, and problem solving $(15,16)$. Nevertheless, the adoption of self-care behaviors must also consider the social context in which adolescents live, in order to precisely tackle the challenges that accompany their sexuality (17).That is the reason why the learning material of the KDW program was adapted to give information in the language and style of teens, as well as to deliver all interventions in the school facilities, were adolescents spend most of their lives, having the chance to exchange information, worries and experiences with their peers. As fact, the workshop design, conceptual clarity, and the personnel entrusted to facilitate the processes were the most valued aspects by participants. It was fundamental for scholars to be able to discuss openly and straightforwardly about sexuality, HIV/AIDS and condom use, and to be able to keep educational materials for later distribution and sharing among their peers.

The analysis of the program KDW revealed a positive impact on social skills and knowledge about HIV/STI and some issues of the SRH of teens who attended the program in a regular basis. Similarly, the Chilean program "Adolescence Decisions Time" (18), demonstrated that after the intervention students with no previous sexual experiences had the greatest improvement in their SRH knowledge, and females expressed the most receptivity. Again, adding to previous evidence, were a positive relationship between improving knowledge on SRH and the development of skills for the maintenance of healthy sexual behaviors is established $(5,19)$.

Interesting, condom use and its negotiation remain difficult for youth. Condom is recognized as a key prevention strategy, though females express that condom negotiation and sexual decision-making processes still proved difficult to them; while males admitted that cultural and social factors interfered with their intention and frequency of using condoms, or alcohol consumption (19). This constitutes a contradiction between what teens learn and what they put into practice in their daily lives, proving that some skills require more time to be learned and implemented. Further, highlights the importance of the role of sexual partners and friends, as reinforcement and as influencing factors, for high-risk behaviors and low control of alcohol consumption. Previous evidence $(2,16,20-21)$ indicates that although the school-based services for adolescents are cost-effective for the health of young people and society, seeing improvements in assertive behaviors concerning sexuality, reproduction and mental health in real-life scenarios requires continuous support. That is, the presence and support of educational and health programs, parents and teachers to empower teens against social pressures.

Therefore, for future interventions, we suggest to strengthen the pleasant associated with a protected intercourse by using of different types of condoms and the double protection provided, against pregnancy and STI. Other important strategy could be the realization of focus groups in company with pregnant adolescents, adolescent who already are parents, and people living with asymptomatic infections like $\mathrm{HIV}$, hepatitis or genital herpes, in order to share their experiences in the very same language that adolescents communicate. Furthermore, values surrounding SRH must be kept in context with the way adolescents grow up, and it is fundamental that social and cultural dynamics are considered as significant influences on their attitudes and practices; which sometimes could imply working separately with females and males groups.

\section{LIMITATIONS}

As limitations of the study, it was encountered a difference in the social stratum and educational level of the experimental group, although this difference did not affect the dynamics of the workshops or focus groups. Here, during the activities it was observed that older scholars have more precise information about SRH and were more confident to share it with other participants, giving the program an opportunity to have their own multiplying peers. Additionally a gender difference was observed among the participants. Namely, females were more analytical while males were more pragmatic and concrete in their commentaries, reflecting the common differences between the psychological development of girl and boys of same age. Finally, the short duration of the program was recognized by participants as a predominant limitation.

\section{CONCLUSIONS}

The "Know and Do to be Well" Program achieved a good level of impact on the adolescents, especially in the acquisition of knowledge and differentiation of protective factors for SRH; skills for open dialogue about these topics; the aptitude to recognize the social and cultural meanings encompassing sexuality and 
the strengthening of social skills for better social interaction. It is our belief that KDW and other educational programs must continue to work on empowering young people during this delicate and crucial moment of their life cycles, strengthening their capacity for decision making and enforcing assertive behaviors, so that they may enjoy a healthier sexual life.

\section{ACKNOWLEDGMENTS}

To all the Schools and adolescents for their active participation and enthusiasm. To Diana Palma, for providing writing services.

\section{REFERENCES}

[1] Profamilia Colombia. Encuesta Nacional de Demografía y Salud 2010. Bogotáhttp://www.profamilia.org.co/encuestas/Profamilia/Profamilia/index.php?option=com_co ntent\&view=article\&id=62\&Itemid=9.. Accessed November 10, 2012.

[2] Uribe AF, Bermúdez MP, Buela-Casal G. Evaluación de factores psicosociales de riesgo para la infección por el VIH/sida en adolescentes colombianos. Tesis DoctoralUniversidad de granada. 2005.

[3] Rodriguez-López A. Prevención en salud mental y antropología cultural. In Buela-Casal G, Fernandez-Rios L, Carrasco T, ed. Psicología Preventiva, avances recientes en técnicas y programas de prevención. Madrid: Ediciones Pirámide; 1997:99-104.

[4] Organización Mundial de la Salud y Organización Panamericana de la Salud: Estrategia de Cooperación con Colombia 2006-2010. Washington D.C. OPS/OMS, 2006. Available at: http://www.who.int/countryfocus/cooperation_strategy/ccs_col_es.pdf. Accessed November 12, 2012.

[5] Bangdiwala S. Evaluación de programas de intervención para la prevención de accidentes en ambientes laborales: consideraciones estadísticas. Rev CiencTrab 2006; 8(19):31-6.

[6] Maddaleno M, Morello P, Infante F. Salud y desarrollo de adolescentes y jóvenes en Latinoamérica y el Caribe: desafíos para la próxima década. Salud Publica Mex2003; 45(S1):132-9.

[7] Coe G. Comunicación y promoción de la salud. Rev Chasqui 1998; 63(36). ISSN-e 1390-1079. http://dialnet.unirioja.es/ejemplar/336731.

[8] Pham V, Nguyen H, Tho LH, et al. Evaluation of three adolescent sexual health programs in Ha Noi and KhanhHoa province, Vietnam. AIDS Res Treat 2012. http://dx.doi.org/10.1155/2012/986978.

[9] Caballo V, editor. Manual para la evaluación clínica de los trastornos psicológicos.Madrid: Ediciones Pirámide; 1994.

[10] Zukerman M, Eysenck SBG, Eysenck HJ. Sensation seeking in England and America: Crosscultural, age, and sex comparisons. J Consult Clinic Psychol 1978; 46(1):139-149.

[11] Jerusalem M, Schwarzer R. Self- efficacy as a resource factor in stress appraisal processes. In R. Schwarzer, ed. Self-efficacy: Thought control of action.Washington, DC: Hemisphere; 1992.

[12] López-Rosales F, Moral-de la Rubia J. Validación de una escala de auto eficacia para la prevención del SIDA. Salud Publica Mex. 2001. http://dx.doi.org/10.1590/S003636342001000500006.

[13] Seisdedos N. Cuestionario A-D: Conductas antisociales-delictivas. Departamento de I+D, ed. TEA Ediciones S.A. Madrid; 1988.

[14] Bernal, R. Peña, X. Guía práctica para la evaluación de impacto. Ediciones Uniandes Bogotá D C; 2011.http://dx.doi.org/10.1590/S1020-49892012000400009.

[15] O'Leary A, Maibach E. Ambrose T, Jemmott III JB, Celentano DD. Social cognitive predictors of sexual risk behavior change among STD clinic patients. AIDS Behavior2004; 4(4): 309-316. http://dx.doi.org/10.1023/A:1026474804172.

[16] Mason-Jones AJ, Crisp C, Momberg M, et al. A systematic review of the role of school-based healthcare in adolescent sexual, reproductive, and mental health. System Rev 2012; 1: 49. http://dx.doi.org/ 10.1186/2046-4053-1-49. 
Ana F. Uribe et al.

[17] WHO, UNAIDS, UNICEF: Global HIV/AIDS response - epidemic update and health sector progress towards universal access - progress report 2011.http://www.who.int/hiv/pub/ progress_report2011/summary_en.pdf?ua=1. Accessed on 27 Nov 2014.

[18] Toledo V, Luengo X, Molina R, et al. Impacto del programa de educación sexual: Adolescencia tiempo de decisiones. Sogia 2000; 7(3):73-86.

[19] Ubillos S. Intervención Psicosocial frente al VIH y SIDA. In Blanco A, Rodríguez- Marin E, ed. Intervención Psicosocial.Madrid: Prentice Hall; 2007:103-134.

[20] Aarø LE, Mathews C, Kaaya S, et al. Promoting sexual and reproductive health among adolescents in southern and eastern Africa (PREPARE): project design and conceptual framework. BMC Public Health 2014 14:54http://dx.doi.org/10.1186/1471-2458-14-54.

[21] Elliott L, Henderson M, Nixon C, Wight D. Has untargeted sexual health promotion for young people reached its limit? A quasi-experimental study. J Epidemiol Commun Health 2013; 67:398-404. http://dx.doi.org/10.1136/jech-2012-201034. 